\title{
TI.30.1
}

\section{eduCourse Data Model}

- PDF: internet2-courselD-eduCourse-200505.pdf

- HTML: internet2-courselD-eduCourse-200505.html

- Linked GIF: objStructure-v4.gif

More Information

\begin{tabular}{|c|c|}
\hline Repository ID & TI.30.1 \\
\hline Persistent URL & http://doi.org/10.26869/TI.30.1 \\
\hline Title & eduCourse Data Model \\
\hline Authors & Tom Barton \\
\hline Sponsor & MACE \\
\hline \multicolumn{2}{|l|}{ Review } \\
\hline Status & Legacy \\
\hline Publish Date & $5 / 17 / 2005$ \\
\hline DOI & 10.26869/TI.30.1 \\
\hline \multicolumn{2}{|l|}{ Signature } \\
\hline Deprecated & No \\
\hline \multicolumn{2}{|l|}{ Future Review } \\
\hline \multicolumn{2}{|l|}{ Supersedes } \\
\hline Format & PDF \\
\hline \multicolumn{2}{|l|}{ Related Docs } \\
\hline \multicolumn{2}{|c|}{ Development Location } \\
\hline \multicolumn{2}{|l|}{ IP Framework } \\
\hline Subject Tags & middlewarerescue \\
\hline Notes & \\
\hline
\end{tabular}

